\title{
great ideas, greal problems
}

Luna B. Leopold

Department of Geology and Geophysics

University of California

Berkeley, California 94720

\author{
The Robert E. Horton Lecture, Honolulu, 1974
}

Some years ago when $I$ was in Greece I was given the opportunity to be introduced to Dr. T. Stuart, who was described to me as a man interested in rivers' characteristics as they related to fish habitat. On meeting Stuart, a serious-minded Scot with a twinkle in his eye, I asked him to tell me what kind of work he did.

He replied, "I talk to fish." With some hesitancy I asked if I had heard him correctly. "Indeed," he assured me, " I mean exactly that. Have you ever heard of Lorenz?" I had, as it happens, read the several books by Lorenz long before he was awarded the Nobel Prize.

"Lorenz talks to birds," Stuart said. "I talk to fish."

In the conversation it came out that Stuart had discovered independently several general characteristics of river channels I had worked out previously, but more than that, he had through the study of the life history of trout and salmon, discovered some aspects of the flow of rivers in relation to gravel bars that I had completely overlooked. For example, at low flow much water moves through the gravel of a bar as well as over it, and this subsurface flow is important in supplying oxygen to the developing fish egg lodged between the cobbles below the stream bed level. Once having been told that such subgravel flow exists, the hydraulic reasons were immediately obvious, but I had not perceived this relation because I had been looking only at the river and not at the biota.

This little example is, I think, typical of how new insights into a scientific problem often originate by work not on the specific problem itself but on some related aspect in an entirely different discipline. To be explicit, some of the early work on the meandering pattern of rivers originated in the study of the sinusoidal waves in the pressure pattern at high levels in the atmosphere. Again, the idea of entropy as a concept having application to landscape form had its origin in the study of isentropic charts of the upper atmosphere. Still further, the application of random walks to problems of river channel networks came from consideration of flow streamlines of water moving through a permeable medium from a point source to a point outlet.

These examples are drawn from subjects with which I am personally familiar. Many more examples might be cited from experiences I have heard related by other scientists.

It is this particular strategy, or manner of thinking about a scientific problem, that I perceive in many aspects of the work of Robert E. Horton and, in my opinion, probably accounts in part for the innovative ideas which he introduced tying together meteorological, physiographic, and hydraulic phenomena.

Because this is the first of the lecture series honoring Dr. Horton, I think it appropriate to say a few words about the man himself and record a few little known facets of his career and his work.

Horton's life spanned the 70-year perior between 1875 and 1945. His education was at a small liberal arts college, Albion, where he took a Bachelor of Science degree in 1897. It must have been a good training ground in the physical sciences for he immediately began a career in engineering that was both lucrative and productive.

There seems to be no question that his life work was importantly influenced by his mother's brother, George Rafter, an engineer of prominence who was of an intellectual as well as practical bent. Rafter was a civil engineer on the Erie Canal, was a pioneer in stream biology, and invented a long used method of making biologic examination of water samples. Rafter published 175 papers and discussions during a lifetime of engineering practice, a combination of intellectual and practical work that was closely followed by Robert E. Horton.

Rafter and Horton jointly published in 1896 a report for the New York State Engineer and Surveyor. This indicates that Horton was already involved in research and publication before he had even graduated from college.

In 1899 Rafter had arranged for hydraulic experiments to be carried out at the laboratory of Cornell University to extend knowledge on the coefficients of weirs needed in connection with hydraulic design work being carried on by the U.S. Board of Engineers on Deep Waterways. Horton was working for the Board at the time, probably in the section administered by Rafter, for Horton was detailed from that Board to Cornell to do part of the computational work connected with the hydraulic tests. The data were published by the American Society of Civil Engineers in 1900 in a paper by Rafter.

Horton must have been very interested in this assignment. There was, at that time, a much smaller number of stream-gaging stations than presently exist, but because so much design work was going on there was an imperative need for far more data on stream flow. A large 
number of New England streams were dammed to provide hydraulic head for power plants many of which served individutl manufacturing firms. The flow over these dams and through their power penstocks was recorded in terms of head, but the translation of these depth data to discharge required rating curves for the weirs and for the water wheels. To improve the knowledge of coefficients for flow through turbines and over dams therefore was of great importance in advancing the hydrologic knowledge concerning eastern river basins.

Robert E. Horton was appointed in 1900 District Engineer of the New York District of the U.S. Geological Survey. He soon persuaded the Washington supervisors that the U.S.G.S. should pursue further the hydraulic experiments started at Cornell for the purpose of extending the use of available data of flow over dams to the determination of river discharge. As a result of his efforts, the Survey assigned him to the Cornell Laboratory in 1903 where he investigated the effect of end contractions on the coefficients in the Francis formula for flow over weirs. These Cornell data extended the basic work on the subject begun by Bazin at a site near Dijon, France, and the later work carried on by Francis on the Concord River near Lowell, Mass.

The resulting report was no doubt the most extensive single piece of work Horton did for the Geological Survey, and has stood ever since as the standard work on the subject, "Weir experiments, coefficients, and formulas," Water Supply Paper 150 published in 1906. It was revised and republished as Water Supply Paper 200, in 1907.

While District Engineer for the Survey, Horton with several others including the great geographer, Isaiah Bowman, published Professional Paper 44, "Underground water of Long Island, New York." Horton's contribution included a set of vertical velocity curves for Sampawams Creek, in which he found that the position of mean velocity in a river cross section was at a level 0.6 of the distance from the surface to the stream bed. Incidently, the next detailed investigation of the same matter was carried out at the Grand Canyon station on the Colorado River in 1922.

To meteorologists, Horton is best known as an early supporter of the idea of a limiting maximum storm and thus flood. His interest in this subject eventually led to the establishment of the Hydrometeorological Section of the U.S. Weather Bureau, devoted to constructing the maximum possible storm for a river basin. This result was accomplished in the mid 1940's, but to indicate the earlier origin, I cite the Horton discussion of the 1926 paper by C. S. Jarvis, "Flood flow characteristics" (Trans. Amer. Soc. Civil Engrs. paper no. 1589). Horton wrote, "Rain can only be produced as fast as moist ascending air currents can be brought over an area.

"There is for each drainage basin a certain finite rate of flood discharge which Nature is incapable of transcending, that is, the true maximum discharge."

Furthermore he showed that storms approaching the maximum limiting envelope are quite within our experience. Regarding the Connecticut River at Hartford, he said, ". . . floods having magnitudes of more than $75 \%$ of the limiting flood magnitude occur at fairly short intervals, in this case about once in eight years" (Jour. New Engl. Water Works Assoc., 38, 1924).

What I wish here to stress is the relatively long gestation period that often is required for the emergence of a distinctly new idea. Its emergence at all often is the result of two factors, 1) continual thinking across disciplinary lines, and the application of concepts from one field to a distinctly different one, and 2) the continual admixture of practical work and application with theoretical and purely intellectual concerns. Well might the modern research man ponder this history.

Because Robert Horton is best known for his pioneering paper in the Bulletin of the Geological Society of America in 1945, some words about the origin of those ideas are in order. But before such comment, note this example of the interdisciplinary thought to which I have just referred. Horton, the successful practicing engineer, is known in science for a paper published in a geological journal. There is reason to believe that he knew that he was on important new ground and that the submission of that manuscript was in his own mind the culmination of his life work. He died the same year as its publication, and he never was to see the revolution in approach which he was there initiating. But his importance in geologic thought was apparently already known for, well before that 1945 paper was published, he was recommended for fellowship in the Geological Society of America by none other than William W. Rubey, dean of the melding of hydraulic and geologic concepts regarding drainage basins and rivers.

In 1921 in a discussion of the probable variation in yearly precipitation published in Transactions American Society of Civil Engineers, he noted the “. . . value of the study of the hydrophysical as well as the statistical relations in such matters." The word hydrophysical appears again in the title to his famous 1945 paper.

In the 1926 discussion of the Jarvis paper, Horton fired his first salvo at the existing concepts of drainage basin development. He listed those physiographic factors he believed related to flood discharge, including drainage density, slope of channels, slope of ground surface, slope ratio (channel to ground surface), length of overland flow. There he noted the reciprocal relation of drainage density to distance between streams, and developed a formula for length of overland flow.

Horton meanwhile had maintained his interest in meteorological problems. Well after he had served as president of the American Meteorological Society, he published in the Bulletin of that society a discussion of the relation of soil conservation to air and groundwater pollution (1943). He was concerned about residual chlorine left in water after municipal water treatment. Typical of his attitude, he wrote, "It is time 
someone found out about it, and whether its effects are cummulative or not."

I had the opportunity to work briefly under Horton in 1938 when he and W. W. Horner were developing jointly a procedure for the analysis of sprinkled plot infiltration tests. I and several other young hydrologists worked on computations concerned with the effect of antecedent moisture on infiltration rate. Interestingly this is a subject under active discussion again at the present time in connection with the newer variable source or partial area concept of surface runoff generation.

It was in 1940, 5 years before publication of his major paper, that Horton apparently felt sure enough of his thesis to expose it to public discussion. He presented in Section $\mathrm{E}$ of the American Association for Advancement of Science at the Philadelphia meeting a part of what was included in the Geological Society paper. His abstract, the only thing published from the 1940 presentation, was entitled, "Hydrophysical approach to quantitative morphology of drainage basins." In it he dealt with the drainage net and its relation to overland flow.

I have the impression that there is a widespread and perhaps unthinking assumption that science progresses from the isolation of the ivory tower and that to be a good research man one must disdain the market place and the practical. It is seldom stated that although the ivory tower provides time for thought (or should do so) and freedom from interruption, it also implies isolation, and isolation is the antithesis of interdisciplinary exchange. I maintain that the good research man is the one who asks himself the right question.

The questions to be answered are manifold and the sorting of good from bad, productive from unproductive, important from less important, is greatly assisted by exposure to science and technology far removed from one's own specialty. Mixing it up with the practical problems of the world would do wonders for many research men I know.

Further, it often happens that the very techniques one develops in his own field are just the ones needed for solution of some problems far distant in subject matter. For example, one of the great problems in the environment of man concerns the description, ranking, and evaluation of the non-monetary values of man's surroundings, the aesthetic and the visual. Such evaluation is a natural for the techniques used as a matter of course by the meteorologist, hydrologist and geomorphologist. These involve mapping, description of attributes or categories, correlation techniques - in short, the stock-in-trade of many physical scientists. This type of thinking is vitally needed to add new dimensions to the usual approach through economics and the purely artistic methodologies.

A minor example of such diversion into the field of non-monetary values is my Geological Survey Circular 620 , on "Quantitative comparison of some aesthetic factors among rivers."

As demonstrated by the success of men like Stuart (behavioral aspects of salmonids and river characteristics) and Horton (geomorphology, hydraulics, and soils), there are new things to be done by the physical scientist who will move into new combinations including biology, pedology, climatology, behavioral science, and aesthetics.

Interdisciplinary work too often means a team approach, each man staying within his own specialty and depending on conversation to bridge the gaps between sciences. It seems equally or perhaps more fruitful to have individual scientists become knowledgeable at some depth in several disciplines. Though this may seem an impossible task in an era of geometrically expanding knowledge, the importance of emerging problems requires rethinking the impossible. 